\title{
Fitoplancton de cinco embalses de Venezuela con diferentes estados tróficos
}

\author{
Ernesto J. González, Mario Ortaz, Carlos Peñaherrera, Enrique Montes, \\ María L. Matos y Janin Mendoza
}

Universidad Central de Venezuela, Instituto de Biología Experimental, Apartado 47106 Los Chaguaramos, Caracas, 1041 - Venezuela. Fax: 58-212-7535897. E-mail: ergonza@reacciun.ve

\section{RESUMEN}

Se estudiaron las variaciones de abundancia, biomasa y producción primaria del fitoplancton en cinco embalses de la zona norte de Venezuela empleados para el suministro de agua potable, y que poseen diferentes estados tróficos: Pao-Cachinche, Quebrada Seca, La Mariposa, La Pereza y Lagartijo. Los muestreos se realizaron en diferentes momentos entre septiembre de 1997 y agosto de 1999. El fitoplancton se recolectó con una botella de captación del tipo van Dorn (3 1), y se fijó con solución de lugol hasta la posterior cuantificación de abundancia por sedimentación en cámaras de Utermöhl y conteo con la ayuda de un microscopio invertido. La biomasa se estimó mediante la extracción de clorofila- $a$ con etanol y la producción primaria se estimó mediante la evolución de la concentración del oxígeno disuelto en botellas claras y oscuras e incubación "in situ" por dos horas. En Pao-Cahinche (hipereutrófico) se identificaron 59 especies del fitoplancton, Cyanobacteria fue el grupo dominante, la abundancia varió entre $25,9 \times 10^{9}$ y $410,2 \times 10^{9}$ org. $\mathrm{m}^{-2}$, la biomasa entre 32,4 y $186,6 \mathrm{mg} \mathrm{m}^{-2}$, mientras que la producción primaria bruta (PPB) promedio fue de 3229 y $2482 \mathrm{mg} \mathrm{C} \mathrm{m}^{-2} \mathrm{~d}^{-1}$ en las estaciones E1 y E2, respectivamente. En La Mariposa (hipereutrófico) se identificaron 50 especies, las Cryptophyta dominaron, la abundancia varió entre $6,2 \times 10^{9}$ y $35,5 \times 10^{9}$ org. $\mathrm{m}^{-2}$, el máximo valor de biomasa fue de $161,8 \mathrm{mg} \mathrm{m}^{-2}$, y la PPB varió entre 968 y $2633 \mathrm{mg} \mathrm{C} \mathrm{m}^{-2}$ $\mathrm{d}^{-1}$. En Lagartijo (oligotrófico) se identificaron 67 especies, siendo las algas verdes las más diversas y las dominantes; la abundancia fue relativamente baja en este ecosistema, con valores entre $4,7 \times 10^{9}$ y $27,2 \times 10^{9} \mathrm{org}^{-2} \mathrm{~m}^{-2}$; la biomasa varió entre 0,01 y $50,0 \mathrm{mg} \mathrm{m}^{-2}$, mientras que los valores de PPB variaron entre 376 y $2088 \mathrm{mg} \mathrm{C} \mathrm{m}^{-2} \mathrm{~d}^{-1}$. En La Pereza (eutrófico) se identificaron 48 especies, Cryptophyta dominó, la abundancia varió entre $26,7 \times 10^{9}$ y $102,9 \times 10^{9}$ org. $\mathrm{m}^{-2}$, la biomasa varió entre $5,5 \mathrm{mg} \mathrm{m}^{-2}$ y $199,2 \mathrm{mg} \mathrm{m}^{-2}$ y la PPB entre 265 y $5619 \mathrm{mg} \mathrm{C} \mathrm{m}^{-2} \mathrm{~d}^{-1}$. En Quebrada Seca (hipereutrófico) se identificaron 48 especies, y Cyanobacteria dominó el fitoplancton; la abundancia varió entre 26,9 x $10^{9}$ y 69,3 x $10^{9}$ org. $\mathrm{m}^{-2}$, la biomasa entre 53,7 y $355,4 \mathrm{mg} \mathrm{m}^{-2}$ y la PPB entre 1763 y $3494 \mathrm{mg} \mathrm{C} \mathrm{m}^{-2} \mathrm{~d}^{-1}$. La mayoría de los embalses evaluados empleados para el suministro de agua potable se encuentran eutrofizados, y en ellos predominan las Cyanobacteria y las Cryptophyta, con elevados valores de abundancia, biomasa y producción primaria, como consecuencia de la entrada excesiva de nutrientes desde sus cuencas de drenaje altamente erosionadas e intervenidas y a través de las aguas servidas sin tratamiento previo.

Palabras claves: Eutrofización, fitoplancton, abundancia, biomasa, producción primaria, Venezuela.

\section{ABSTRACT}

Seasonal variations of phytoplankton abundance, biomass, and primary production were studied in five drinking water reservoirs located in the northern region of Venezuela, and that show different trophic states: Pao-Cachinche, Quebrada Seca, La Mariposa, La Pereza y Lagartijo. Samples were taken at different moments from September 1997 to August 1999. Phytoplankton was collected with a van Dorn type bottle (3 l) and fixed with lugol solution until later abundance quantification by sedimentation with Utermöhl chambers, and counting with inverted microscope. Biomass was estimated by chlorophyll-a extraction with ethanol, and primary production was estimated by dissolved oxygen evolution in light and dark bottles and "in situ" incubation for two hours. A total of 59 phytoplankton species were identified in Pao-Cachinche (hypertrophic); Cyanobacteria was the dominant group, abundance ranged between $25.9 \times 10^{9}$ and $410.2 \times 10^{9} \mathrm{cells}^{-2}$, biomass ranged between 32.4 and $186.6 \mathrm{mg} \mathrm{m}^{-2}$, while mean gross primary production (GPP) were 3229 and $2482 \mathrm{mg} \mathrm{C} \mathrm{m}^{-2}$ $d^{-1}$ in stations E1 and E2, respectively. In La Mariposa (hypertrophic), a total of 50 species were identified; Cryptophyta dominated, abundance ranged between $6.2 \times 10^{9}$ and $35.5 \times 10^{9} \mathrm{cells} \mathrm{m}^{-2}$, the highest biomass value was $161.8 \mathrm{mg} \mathrm{m}^{-2}$, and GPP ranged between 968 and $2633 \mathrm{mg} \mathrm{C} \mathrm{m}^{-2} \mathrm{~d}^{-1}$. A total of 67 species were identified in Lagartijo (oligotrophic), being green algae the dominant and more diverse group; abundance was relatively low in this ecosystem, and ranged between 
$4.7 \times 10^{9}$ and $27.2 \times 10^{9}$ cells $\mathrm{m}^{-2}$; biomass ranged between 0,01 and $50,0 \mathrm{mg} \mathrm{m}^{-2}$, while GPP varied from 376 to $2088 \mathrm{mg} \mathrm{C}$ $m^{-2} d^{-1}$. In La Pereza (eutrophic), a total of 48 species were identified; Cryptophyta was the dominant group, abundance varied between $26.7 \times 10^{9}$ and $102.9 \times 10^{9}$ cells m-2 biomass ranged between $5.5 \mathrm{mg} \mathrm{m}^{-2}$ and $199.2 \mathrm{mg} \mathrm{m}^{-2}$ and GPP ranged between 265 and $5619 \mathrm{mg} \mathrm{C} \mathrm{m}^{-2} d^{-1}$. A total of 48 phytoplankton species were identified in Quebrada Seca (hypertrophic);

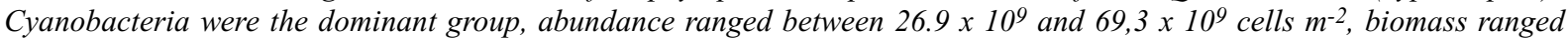
between 53.7 and $355.4 \mathrm{mg} \mathrm{m}^{-2}$, and GPP ranged between 1763 and $3494 \mathrm{mg} \mathrm{C} \mathrm{m}^{-2} \mathrm{~d}^{-1}$. Most of these reservoirs that are employed for drinking water supply are eutrophic and Cyanobacteria and Cryptophyta were the dominant phytoplankton groups with elevated abundance values, biomass, and primary production as a result of the high nutrient input from their highly erosionated basins and from waste water without previous treatment.

Keywords: Eutrophication, phytoplankton, abundance, biomass, primary production, Venezuela

\section{INTRODUCCIÓN}

Los problemas asociados con la eutrofización son generalmente de experiencia reciente en los países tropicales (Harper, 1992). La construcción de embalses nuevos para el suministro de agua potable, aunado al aumento de asentamientos humanos en sus cuencas de drenaje, han resultado en un amplio espectro de problemas, con el consecuente incremento acelerado en la entrada de nutrientes.

Las masas de agua eutróficas se caracterizan por tener una productividad elevada y altos valores de biomasa en todos los niveles tróficos (Ryding \& Rast, 1992). En estos cuerpos de agua proliferan las cianobacterias, y el hipolimnion presenta condiciones de anoxia durante los períodos de estratificación térmica, y a menudo poseen menos especies de plantas y animales que los sistemas oligotróficos.

En el caso de los cuerpos de agua empleados para el suministro de agua potable, los altos niveles de nutrientes producen el crecimiento excesivo de algas, las cuales pueden conferir olores desagradables al agua (Edmondson, 1969), además de bloquear los filtros en las estaciones de tratamiento y bombeo, lo cual encarece y retarda el tratamiento del agua (Ryding \& Rast, 1992).

En Venezuela existen numerosos embalses en los que se desconocen completamente sus características limnológicas (González, 2000), por lo que se hace necesario conocer el funcionamiento de estos ecosistemas, para así lograr un aprovechamiento racional de ellos (Infante et al., 1992, Infante et al., 1995).

Los embalses seleccionados en este estudio (Pao-Cachinche, La Mariposa, Lagartijo, La Pereza y Quebrada Seca), se emplean para el suministro de agua potable para densas regiones urbanas de la región centro - norte de Venezuela. En la mayoría de ellos se presentan grandes densidades de algas, especialmente de cianobacterias, que causan los problemas antes descritos.

En vista de lo anterior, y dado el interés de las compañías hidrológicas Hidroven, Hidrocentro e Hidrocapital en conocer las características limnológicas de los cinco embalses citados, se planteó el objetivo de estudiar las variaciones de abundancia, biomasa y producción primaria de esta comunidad en cada uno de los embalses.

\section{MATERIALES Y MÉTODOS}

En cada embalse se estimó la producción primaria del fitoplancton mediante el método de la evolución de oxígeno en botellas claras y oscuras, e incubación "in situ" por dos horas (Wetzel \& Likens, 1991). Las muestras se tomaron con una botella de captación del tipo van Dorn (3 1) hasta tres veces la profundidad del disco de Secchi.

Las muestras de fitoplancton se recolectaron con la botella de captación del tipo van Dorn (3 1) a las mismas profundidades a las cuales se estimó la producción primaria. Para la determinación de abundancia, las muestras se fijaron 
con solución de lugol en envases de $100 \mathrm{ml}$, mientras que para la determinación de biomasa, las muestras se almacenaron en envases de 21 y se mantuvieron refrigeradas y en oscuridad hasta el momento de su análisis en el laboratorio.

Una vez en el laboratorio, la biomasa se estimó como concentración de clorofila- $a$ por el método de extracción de pigmentos con etanol (Nusch \& Palme, 1975).

La abundancia del fitoplancton se estimó por sedimentación en cámaras de Utermöhl y conteo en un microscopio invertido de luz (Wetzel \& Likens, 1991). Su identificación se realizó con la ayuda de claves taxonómicas.

\section{ÁREAS DE ESTUDIO}

Los estudios se realizaron en los embalses PaoCachinche, La Mariposa, Lagartijo, La Pereza y Quebrada Seca, cuyas localizaciones en Venezuela y sus principales características morfométricas se resumen en la Tabla 1.

\section{Embalse Pao-Cachinche}

Está ubicado en la región centro norte de Venezuela, en el límite entre los estados Carabobo y Cojedes, cerca de la ciudad de Valencia, aguas debajo de la confluencia de los ríos Paito y Chirgua, aproximadamente hacia el centro de la cuenca del río Pao. En él confluyen los principales cursos que drenan de la cuenca alta: ríos Chirgua, Paito, Pirapira, Paya y San Pedro. Se encuentra a una cota de 353 m.s.n.m. (Ginez \& Olivo, 1984). Sus aguas se utilizan para agricultura de subsistencia y uso pecuario intensivo y extensivo, además de suministrar agua potable al área metropolitana de Valencia y otras poblaciones de los estados Carabobo, Cojedes y Aragua. El río Paito transporta aguas residuales y domésticas, mientras que el río Chirgua transporta las aguas provenientes de granjas avícolas y porcinas. El embalse está rodeado por más de 50 cochineras y polleras, y recibe una alta carga de nutrientes (especialmente P), principalmente del río Paito.

Se realizaron muestreos mensuales desde septiembre de 1997 hasta febrero de 1999. Se seleccionaron 2 estaciones, ubicadas en el brazo oeste y en el brazo este del embalse, los cuales se encuentran separados por un canal estrecho. En el brazo oeste se encuentran el dique, el aliviadero y la torre-toma, y se ubicó la estación denominada E1. La estación ubicada en el brazo este se denominó E2.

\section{Embalse La Mariposa}

El embalse está ubicado en el Distrito Capital, en la ciudad de Caracas. La mayor parte del agua que recibe el embalse proviene del río $\mathrm{El}$

Tabla 1. Características morfométricas de los embalses estudiados. Morphometric features of the studied reservoirs.

\begin{tabular}{llllll}
\hline & Pao-Cachinche & La Mariposa & Lagartijo & La Pereza & $\begin{array}{l}\text { Quebrada } \\
\text { Seca }\end{array}$ \\
\hline Ubicación geográfica & $\begin{array}{l}9^{\circ} 53^{\prime} \mathrm{N} \\
68^{\circ} 08^{\prime} \mathrm{W}\end{array}$ & $\begin{array}{l}10^{\circ} 24^{\prime} \mathrm{N} \\
66^{\circ} 33^{\prime} \mathrm{W}\end{array}$ & $\begin{array}{l}10^{\circ} 11^{\prime} \mathrm{N} \\
66^{\circ} 43^{\prime} \mathrm{W}\end{array}$ & $\begin{array}{l}10^{\circ} 27^{\prime} \mathrm{N} \\
66^{\circ} 46^{\prime} \mathrm{W}\end{array}$ & $\begin{array}{l}10^{\circ} 13^{\prime} \mathrm{N} \\
66^{\circ} 43^{\prime} \mathrm{W}\end{array}$ \\
$\begin{array}{l}\text { Area del } \\
\text { embalse }\left(\mathrm{m}^{2}\right)\end{array}$ & 16100000 & 540000 & 4550000 & 562500 & 950000 \\
$\begin{array}{l}\text { Volumen del } \\
\text { embalse }\left(\mathrm{m}^{3}\right)\end{array}$ & 170000000 & 7000000 & 80000000 & 8000000 & 7250000 \\
$\begin{array}{l}\text { Profundidad media (m) } \\
\text { Tiempo de } \\
\text { renovación (días) }\end{array}$ & 10.6 & 13.0 & 17.5 & 14.0 & 7.6 \\
\hline
\end{tabular}


Valle al cual le vierten una considerable cantidad de agua bombeada desde el embalse Lagartijo mediante el Sistema Tuy. El embalse también recibe aguas de una pequeña quebrada conocida como Quebrada Los Indios ubicada en la zona oriental del mismo. El embalse está situado a 980 m.s.n.m. y su cubeta es alargada con dos brazos principales al sur y al este correspondientes a las desembocaduras del río El Valle y la Quebrada Los Indios, respectivamente. El embalse se encuentra intervenido antrópicamente y su cuenca está altamente erosionada (González \& Ortaz, 1998).

Se realizaron muestreos mensuales de septiembre de 1998 a agosto de 1999. Las muestras se tomaron en la estación ubicada frente al dique y frente a la torre-toma.

\section{Embalse Lagartijo}

Se encuentra ubicado en el estado Miranda. Su principal tributario es el río Lagartijo, que aporta aproximadamente $3000 \mathrm{l} / \mathrm{s}$ (promedio anual) de agua relativamente limpia ya que este río nace dentro del Parque Nacional Guatopo, de modo que buena parte de su recorrido ocurre dentro de una zona protegida. El embalse además recibe de manera artificial agua bombeada desde el río Tuy, la cual antes de entrar al embalse es sometida a un tratamiento de sedimentación y cloración. Según Infante et al. (1992) el agua bombeada desde el río Tuy entra por un lugar que se encuentra cerca del punto de toma de agua que se envía para Caracas y posiblemente por esta razón, su efecto se deja sentir localmente, sin afectar significativamente las condiciones del agua en el resto del embalse.

El embalse Lagartijo es de baja altitud (188 m.s.n.m.) y muy dendrítico con pendientes pronunciadas en las montañas adyacentes de modo que la zona litoral, al igual que en el embalse La Mariposa, está poco desarrollada.

Los muestreos se realizaron de septiembre de 1998 a julio de 1999 en una estación cercana a uno de los diques del embalse, lejana de la zona de influencia del punto afectado por el río Tuy.

\section{Embalse La Pereza}

Este embalse se encuentra ubicado en el estado Miranda a una cota de 1062 m.s.n.m. (Castillo et al., 1973). Su principal función es el suministro de agua potable a las poblaciones aledañas al área metropolitana de Caracas. Este embalse es el más pequeño de los cinco estudiados, y recibe agua de la quebrada La Pereza y, principalmente, de la proveniente de otros embalses del sistema Tuy.

Sus alrededores están muy intervenidos, con una alta erosión en las laderas contiguas. Así mismo, se pudo observar la descarga al embalse de aguas de desecho de origen doméstico e industrial, y fue evidente la presencia de cochineras en áreas aledañas así como de ganado vacuno. Todos los productos de desecho de las fuentes citadas son vertidas al embalses o arrastradas a él por escorrentía.

Los muestreos se realizaron en noviembre de 1998, febrero, abril, mayo y junio de 1999. Las muestras se tomaron en una localidad ubicada frente al dique.

\section{Embalse Quebrada Seca}

Este embalse se encuentra ubicado cerca del embalse Lagartijo en el estado Miranda, a una cota de 167 m.s.n.m. (Castillo et al., 1973). Está rodeado de construcciones no planificadas y depósitos de basura en sus alrededores, lo que lo hace muy vulnerable a cualquier tipo de actividad contaminante.

Los muestreos se realizaron durante los meses de octubre y diciembre de 1998, y en marzo, mayo y junio de 1999. Las muestras se tomaron en una localidad frente al dique.

Los embalses La Mariposa, Lagartijo, La Pereza y Quebrada Seca se encuentran interconectados mediante el sistema Tuy, un sistema de bombeo de agua entre los embalses de la cuenca del río Tuy.

\section{RESULTADOS Y DISCUSIÓN}

En la Tabla 2 se presentan algunas características físicas y químicas de los embalses estudia- 
Tabla 2. Algunas características físicas y químicas de los embalses estudiados. Los promedios se colocan entre paréntesis. Datos tomados de Ortaz et al. (1999) para los embalses La Mariposa, Lagartijo, La Pereza y Quebrada Seca, y de González et al. (2000) para el embalse PaoCachinche. Some physical and chemical features of the studied reservoirs. Mean values in parenthesis. Data from Ortaz et al. (1999) for La Mariposa, Lagartijo, La Pereza and Quebrada Seca reservoirs, and from Gonzalez et al. (2000) for Pao-Cachinche reservoir.

\begin{tabular}{|c|c|c|c|c|c|c|}
\hline & $\begin{array}{l}\text { Pao-Cachinche } \\
\text { E1 }\end{array}$ & $\begin{array}{l}\text { Pao-Cachinche } \\
\text { E2 }\end{array}$ & La Mariposa & Lagartijo & La Pereza & $\begin{array}{l}\text { Quebrada } \\
\text { Seca }\end{array}$ \\
\hline Mezcla completa & No & No & Sí & No & Sí & Sí \\
\hline Zona eufótica (m) & $1-3$ & $1-3$ & $1-2$ & $2-6$ & $1-4$ & $2-3$ \\
\hline Transparencia (m) & $\begin{array}{l}0.5-1.3 \\
(0.97)\end{array}$ & $\begin{array}{l}0.90-1.50 \\
\quad(1.14)\end{array}$ & $\begin{array}{l}0.3-0.8 \\
(0.60)\end{array}$ & $\begin{array}{l}0.9-5.0 \\
(3.15)\end{array}$ & $\begin{array}{c}0.7-1.9 \\
(1.34)\end{array}$ & $\begin{array}{l}0.6-1.5 \\
(0.98)\end{array}$ \\
\hline $\begin{array}{l}\text { Coef. atenuación } \\
\left(\mathrm{m}^{-1}\right)\end{array}$ & $\begin{array}{l}0.87-2.97 \\
\quad(1.62)\end{array}$ & $\begin{array}{c}0.56-2.01 \\
\quad(1.32)\end{array}$ & $\begin{array}{c}1.46-4.07 \\
(2.24)\end{array}$ & $\begin{array}{l}0.40-1.41 \\
\quad(0.73)\end{array}$ & $\begin{array}{l}0.72-1.47 \\
\quad(1.09)\end{array}$ & $\begin{array}{l}1.02-2.35 \\
(1.59)\end{array}$ \\
\hline $\begin{array}{l}\text { Fósforo } \\
\text { total }(\mu \mathrm{g} / \mathrm{l})\end{array}$ & $\begin{array}{c}280.97-787.99 \\
(462.45)\end{array}$ & $\begin{array}{c}102.72-559.58 \\
(365.93)\end{array}$ & $\begin{array}{c}47.09-241.38 \\
(129.47)\end{array}$ & $\begin{array}{c}15.72-46.86 \\
(24.46)\end{array}$ & $\begin{array}{c}63.27-120.77 \\
\quad(89.82)\end{array}$ & $\begin{array}{c}60.23-346.60 \\
\quad(168.71)\end{array}$ \\
\hline $\begin{array}{l}\text { Nitrógeno } \\
\text { total }(\mu \mathrm{g} / \mathrm{l})\end{array}$ & $\begin{array}{c}1459.56-7164.84 \\
(3583.74)\end{array}$ & $\begin{array}{c}1937.30-14676.51 \\
(4279.64)\end{array}$ & $\begin{array}{c}758.64-2531.67 \\
(1497.19)\end{array}$ & $\begin{array}{c}275.59-754.24 \\
(426.14)\end{array}$ & $\begin{array}{c}790.51-1073.16 \\
(984.83)\end{array}$ & $\begin{array}{c}1538.62-3188.90 \\
(2152.80)\end{array}$ \\
\hline Estado trófico & Hipereutrófico & Hipereutrófico & Hipereutrófico & Oligotrófico & Eutrófico & Hipereutrófico \\
\hline
\end{tabular}

dos, las cuales fueron tomadas de Ortaz et al. (1999) en el caso de los embalses La Mariposa, Lagartijo, La Pereza y Quebrada Seca, y de González et al. (2000) en el caso del embalse Pao-Cachinche.

El embalse Pao-Cachinche, por estar protegido de la acción del viento, no presentó circulación completa de sus aguas durante el período de estudio. Sus aguas presentaron un color verde turbio debido a la alta turbiedad generada por las densas poblaciones de fitoplancton, las cuales limitaron a su vez la penetración de la luz en la columna de agua en las dos estaciones. Se presentaron condiciones de hipoxia y de anoxia a partir de $7-10 \mathrm{~m}$ de profundidad durante todo el lapso de estudio en ambas estaciones. Las altas concentraciones de nutrientes, especialmente de fósforo total, permitieron clasificar este embalse como hipereutrófico, según el criterio de Salas \& Martinó (1991) para lagos cálidos tropicales.

El embalse La Mariposa presentó circulación completa de sus aguas como producto de la acción del viento durante los meses de enero a marzo de 1999 (estación de sequía). Fue en este período en que se registraron los mayores valores en las concentraciones de nutrientes. De igual modo, la entrada de las lluvias y el bombeo de agua desde otros embalses elevó los valores de los nutrientes a finales del período de estudio. El color de sus aguas fue marrón verdoso y verde oliva, como consecuencia de la alta turbiedad abiogénica, en primer término, que limitó la penetración de la luz en la columna de agua, y a la alta turbiedad biogénica, en segundo término, como consecuencia de las densas poblaciones de fitoplancton registradas. Se registraron condiciones de hipoxia en el hipolimnion hacia finales de la estación de lluvias (septiembre de 1998 y agosto de 1999). Este embalse también se clasificó como hipereutrófico (Salas \& Martinó, 1991).

El embalse Lagartijo fue el que registró los mayores valores de transparencia de sus aguas, debido a que su cuenca se encuentra menos intervenida por estar dentro de un Parque Nacional. Sin embargo, al estar protegido de la acción del viento por las formaciones montaño- 
Tabla 3. Lista de especies del fitoplancton encontradas en el embalse Pao-Cachinche. List of phytoplankton species collected in PaoCachinche reservoir.

\section{Cyanobacteria}

1. Anabaena aphanizomenoides

2. Anabaena spiroides

3. Aphanocapsa sp.

4. Aphanothece nidulans

5. Chroococcus limneticus

6. Chroococcus pallidus

7. Coelosphaerium kuetzingianum

8. Coelosphaerium minutissimun

9. Coelosphaerium negelianum

10. Cylindrospermopsis raciborskii

11. Dactylococcopsis acicularis

12. Gomphosphaeria aponina

13. Lyngbya limnetica

14. Limnothrix sp.

15. Merismopedia elegans

16. Merismopedia tenuissima

17. Microcystis aeruginosa

18. Microcystis flos-aquae

19. Microcystis holsatica

20. Oscillatoria limosa

21. Pseudoanabaena mucicola

22. Rhaphidiopsis curvata

23. Spirulina sp.

24. Synechococcus bigranulatus

25. Synechocystis aquatilis

\section{Chlorophyta}

26. Botryococcus braunii

27. Chlorella vulgaris

28. Closterium macilentum

29. Closterium sp.

30. Cosmarium sp.

31. Crucigenia apiculata

32. Crucigenia rectangularis
33. Dictyosphaerium pulchellum

34. Elakatothrix gelatinosa

35. Kirchneriella lunaris

36. Monoraphidium braunii

37. Monoraphidium tortile

38. Nephrocytium limneticum

39. Oocystis lacustris

40. Phacotus lenticularis

41. Pleurotaenium sp.

42. Schroederia setigera

43. Sphaeocystis schroeteri

44. Staurastrum leptocladum

45. Volvox sp.

\section{Bacillariophyta}

46. Aulacoseira granulata

47. Cyclotella sp.

48. Denticula sp.

49. Gomphonema sp.

50. Navicula sp.

51. Rhizosolenia sp.

52. Ropalodia $\mathrm{sp.}$

53. Synedra ulna

\section{Euglenophyta}

54. Euglena variabilis

55. Trachelomonas superba

56. Trachelomonas volvocina

Pyrrophyta

57. Peridinium sp.

\section{Cryptophyta}

58. Chroomonas sp.

59. Cryptomonas erosa sas aledañas, no presentó circulación completa de sus aguas durante el período de estudio, lo cual produjo, a su vez, el desarrollo de condiciones de hipoxia y de anoxia a partir de los $6-7 \mathrm{~m}$ de profundidad. Se registraron bajas concentraciones de nutrientes, y se clasificó como oligotrófico (Salas \& Martinó, 1991).

El embalse La Pereza presentó grandes variaciones en su nivel de agua durante el período de estudio, lo cual es común en este sistema debido al manejo al que es sometido mediante la extracción y bombeo de agua desde y hacia el sistema Tuy, y a su tamaño pequeño. Esto fue registrado por González et al. (1997) en un estudio previo, cuando el embalse disminuyó su nivel en diez metros y luego volvió a incrementarse otros diez metros en meses sucesivos (octubre a noviembre de 1997). Este hecho, más que las funciones de fuerza, dirigen la dinámica de este ecosistema, permitiendo así la mezcla completa de sus aguas. Se presentó, al igual que en La Mariposa, una alta turbiedad abiogénica, en primer término, y una alta turbiedad biogénica, en segundo término. Las altas concentraciones de fósforo total permitieron clasificarlo como eutrófico (Salas \& Martinó, 1991). 
El embalse Quebrada Seca presentó una zona eufótica restringida a unos $2-3 \mathrm{~m}$, producto de la alta turbiedad biogénica (densas poblaciones de fitoplancton). Este embalse presentó circulación completa de sus aguas entre enero y marzo de 1999, lo cual seguramente también fue afectado por la influencia del bombeo de agua desde y hacia el sistema Tuy. Se presentaron condiciones de anoxia a partir de $5-7 \mathrm{~m}$. También se registraron altas concentraciones de fósforo total, lo cual permitió clasificarlo como hipereutrófico (Salas \& Martinó, 1991).

\section{Embalse Pao-Cachinche}

En la Tabla 3 se presenta la lista de las especies del fitoplancton registradas en el embalse PaoCachinche durante el período de estudio. Se lograron identificar 59 taxa, de los que las Cyanobacteria fueron las más diversas con 25 especies, seguidas por las Chlorophyta con 20 especies. Además, se identificaron 8 especies de diatomeas (Bacillariophyta), 3 especies de Euglenophyta, 2 especies de Cryptophyta y 1 especie de Pyrrophyta.
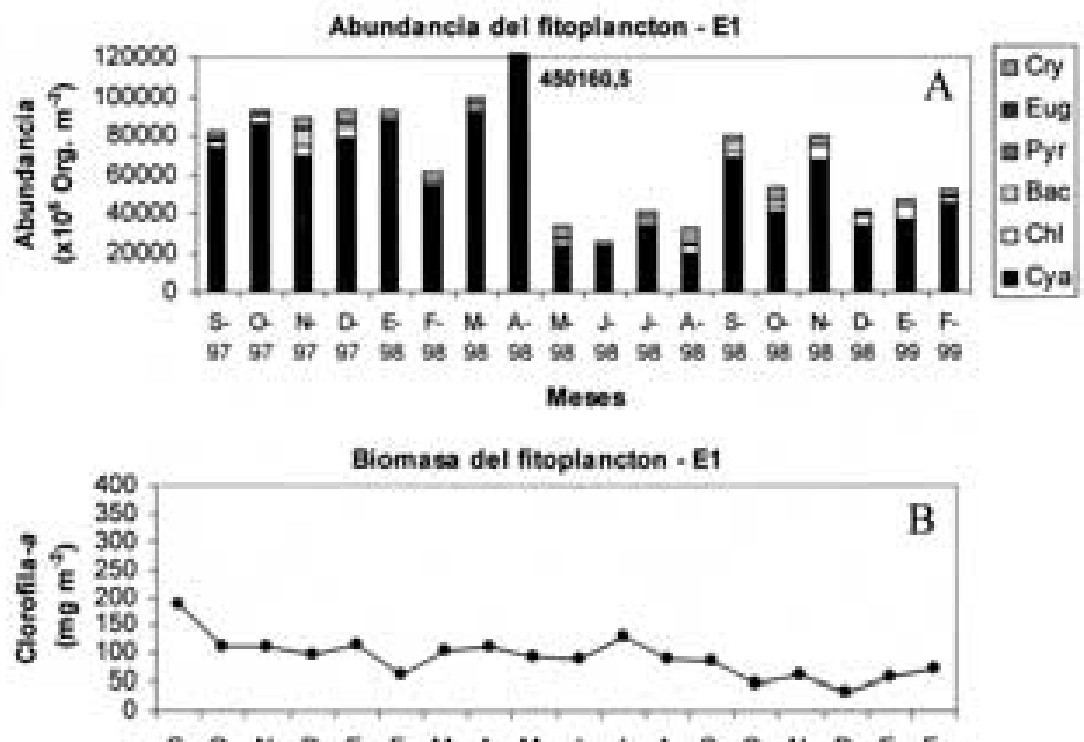

S. O- N. D. E. F. M- A. M. \& J A. S. O- N. D. E. F.

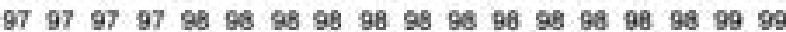

Meses

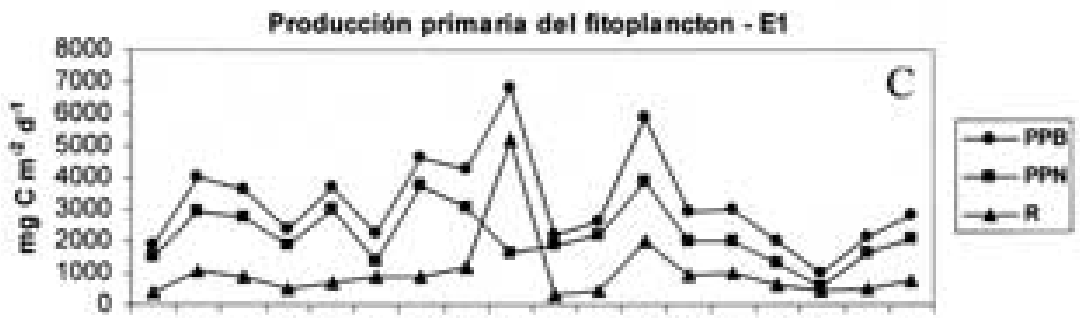

S. O. N. D. E. F. M. A. M. \& \& A. S- O. N. D. E. F.

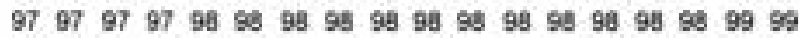

Meses

Figura 1. Fitoplancton del embalse Pao-Cachinche (E1). A. Abundancia, B. Biomasa, C. Producción primaria. Phytoplankton from Pao-Cachinche reservoir (E1). A. Abundance, B, Biomass, C. Primary production. 


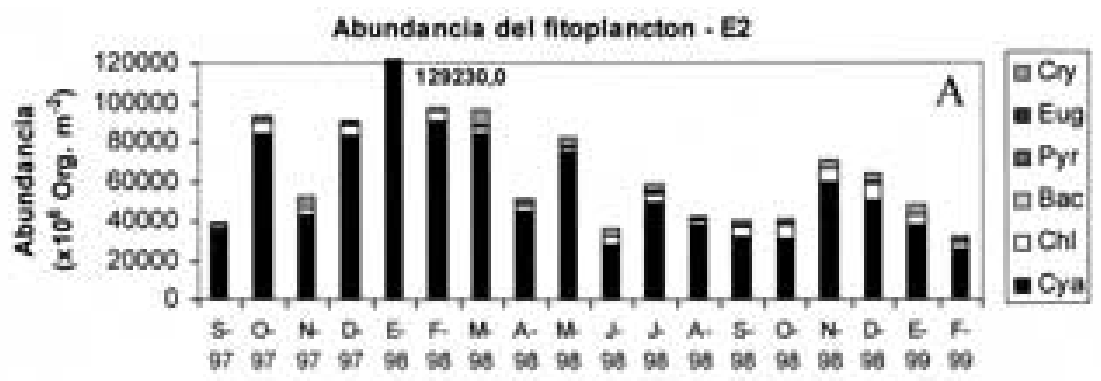

Meses

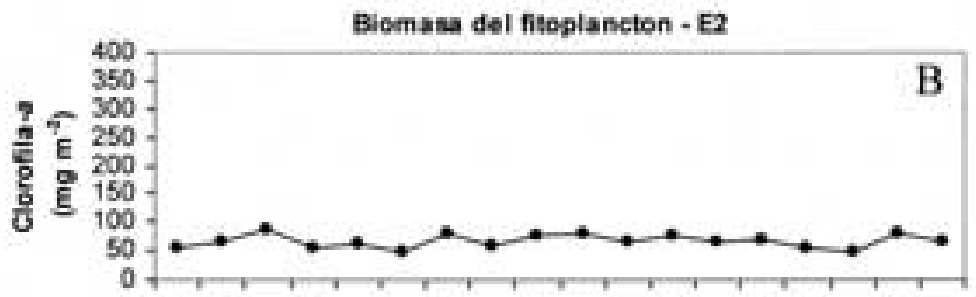

S. O. N- D. E. F. M- A. M. I + A. S- O. N-D. E. F.

979797979898969896989896 so 98 98 969090

Meses

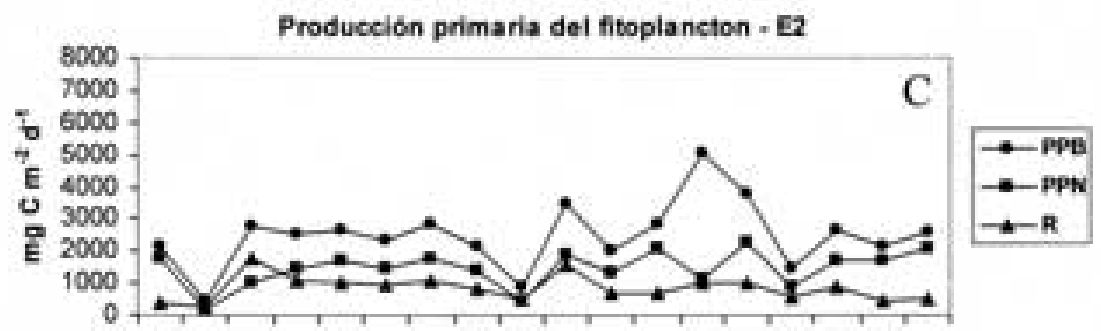

S. O- N.D. E. F. M. A. M. J. J. A. S. O- N. D. E. F.

979797979698989598989898989898969999

Metes

Figura 2. Fitoplancton del embalse Pao-Cachinche (E2). A. Abundancia, B. Biomasa, C. Producción primaria. Phytoplankton from Pao-Cachinche reservoir (E2). A. Abundance, B, Biomass, C. Primary production.

El grupo de las Cyanobacteria dominó el fitoplancton durante todo el período de estudio, tanto en E1 (Fig. 1) como en E2 (Fig. 2), con proporciones relativas siempre superiores al $75 \%$ en ambas estaciones, excepto durante los meses de mayo y agosto de 1998 en E1, cuando representaron poco más del $60 \%$ del total. Las especies dominantes fueron Cylindrospermopsis raciborskii, Synechocystis aquatilis, Lyngbya limnetica, Limnothrix sp., Microcystis spp., Dactylococcopsis acicularis y Rhaphidiopsis curvata. La División Cryptophyta presentó su mayor proporción relativa durante el mes de agosto en E1, mes en el que las Cyanobacteria presentaron su menor proporción relativa. Cryptomonas erosa fue una de las especies codominantes en agosto de 1998.

Los principales representantes de las algas verdes fueron Chlorella vulgaris y Monoraphidium spp. Las Chlorophyta presentaron proporciones cercanas al $10 \%$ durante casi todo el período de estudio. El resto de los grupos tuvo una baja contribución relativa al fitoplancton total. 
La abundancia del fitoplancton se estimó en las dos estaciones limnéticas, y en E1 la mayor abundancia se registró durante el mes de abril de 1998, con valores de $450 \times 10^{9}$ org. $/ \mathrm{m}^{2}$ (Fig. 1A). Este valor extremo se debió a un gran desarrollo o floraciones ("bloom") de las especies Synechocystis aquatilis y Microcystis spp. Por el contrario, la menor abundancia del fitoplancton se registró en junio, con una abundancia de $25.9 \times 10^{9} \mathrm{org} . / \mathrm{m}^{2}$, posiblemente como consecuencia de una menor disponibilidad de nutrientes (principalmente ortofosfatos). También pudo haber influido el hecho de que las aguas de esta estación fueron tratadas con alguicidas y otros químicos (sulfato de cobre, sulfato de aluminio e hipoclorito de calcio) durante el mes de mayo de 1998, a fin de controlar las densas poblaciones de algas. La abundancia promedio del fitoplancton fue de $86,1 \mathrm{x}$ $10^{9} \mathrm{org} . / \mathrm{m}^{2}$ en E1. Este valor puede considerarse bastante elevado.

La biomasa del fitoplancton en E1 varió entre $32.42 \mathrm{mg} / \mathrm{m}^{2}$ (diciembre de 1998) y $186.63 \mathrm{mg} / \mathrm{m}^{2}$ (septiembre de 1997), con un valor promedio de $92.13 \mathrm{mg} / \mathrm{m}^{2}$ (Fig. 1B). Estos valores se pueden considerar elevados. En términos volumétricos, el valor promedio fue de $42.40 \mu \mathrm{g} / \mathrm{l}$.

Se encontró una correlación estadísticamente significativa entre la abundancia del fitoplancton y el coeficiente de atenuación de la luz en $\mathrm{E} 1(\mathrm{r}=0.5081 ; \mathrm{p}<0.05)$, lo que confirmó que las algas fueron responsables en gran medida de la pobre penetración de la luz hacia los estratos más profundos en E1. La transparencia del agua estuvo significativamente correlacionada en forma negativa con la abundancia del fitoplancton (González et al., 2000), reforzando la afirmación anterior $(\mathrm{r}=-0.5623 ; \mathrm{p}<0.05)$. De igual forma, la biomasa del fitoplancton, medida como concentración de clorofila- $a$, también estuvo correlacionada de manera significativa con el coeficiente de atenuación de la luz $(\mathrm{r}=0.5748 ; \mathrm{p}<0.05)$.

Por su parte, en E2 se registraron valores de abundancia del fitoplancton con menores fluctuaciones que en E1 (Fig. 2A). La abundancia de las algas varió entre $31.6 \times 10^{9} \mathrm{org} . / \mathrm{m}^{2}$ (febrero de 1999) y $129.2 \times 10^{9}$ org. $/ \mathrm{m}^{2}$ (enero de 1998), con una media de $64.6 \times 10^{9}$ org. $/ \mathrm{m}^{2}$. Este valor puede considerarse muy elevado, a pesar de ser menor que el determinado para E1.

La variación de la biomasa del fitoplancton en E2 también fue elevada, con valores entre 45.74 $\mathrm{mg} / \mathrm{m}^{2}$ (febrero de 1998) y $85.40 \mathrm{mg} / \mathrm{m}^{2}$ (noviembre de 1997), y un promedio de $65.35 \mathrm{mg} / \mathrm{m}^{2}$ (Fig. 2B). Este promedio también fue menor que el determinado para E1. La concentración de clorofila- $a$ promedio, expresada en unidades volumétricas, fue de $25.08 \mu \mathrm{g} / 1$.

Los mayores valores y las mayores fluctuaciones de abundancia y de biomasa del fitoplancton registrados en la estación ubicada al lado de la torre - toma, en relación con los estimados en la estación ubicada en el brazo este del embalse, pudieran ser el resultado de la presencia de un aliviadero en E1. El fitoplancton en esta región pareció responder rápidamente a la entrada de nutrientes desde los tributarios (especialmente desde el río Paito), pero en los meses en que se dio el flujo de salida del agua por el aliviadero se pudo acelerar la pérdida de nutrientes y de algas a una mayor tasa que en E2, en la que no había aliviadero y en la que las aguas parecieron estancarse un poco como consecuencia del estrecho que separa ambos brazos del embalse, el cual impide un flujo libre de agua entre ambas regiones de este cuerpo de agua.

Las figuras $1 \mathrm{C}$ y $2 \mathrm{C}$ muestran las variaciones de la producción primaria del fitoplancton en E1 y E2, respectivamente. E1 presentó mayores fluctuaciones que E2, probablemente debido a la extracción de agua desde la torre-toma. En este embalse, sólo en E1 las aguas fueron tratadas con alguicidas $\left(\mathrm{CuSO}_{4}\right.$ y $\left.\mathrm{AlSO}_{4}\right)$ y, seguramente, esto también afectó los procesos del fitoplancton. La respiración representó, en promedio, el $32 \%$ y el $34 \%$ de la producción primaria bruta (PPB) en E1 y E2, respectivamente. Los valores promedios de la PPB fueron $3229 \mathrm{mg} \mathrm{C} \mathrm{m}^{-2} \mathrm{~d}^{-1}$ y $2482 \mathrm{mg} \mathrm{C} \mathrm{m}^{-2} \mathrm{~d}^{-1}$ para E1 y E2, respectivamente, que pueden considerarse como valores elevados. 
Tabla 4. Lista de las especies del fitoplancton encontradas en el embalse La Mariposa. List of phytoplankton species collected in La Mariposa reservoir.

\section{Cyanobacteria}

1. Anabaena sp.

2. Aphanocapsa sp.

3. Coelosphaerium kuetzingianum

4. Cylindrospermopsis raciborskii

5. Chroococcus limneticus

6. Chroococcus minutus

7. Dactylococcopsis acicularis

8. Gomphosphaeria aponina

9. Lyngbya limnetica

10. Microcystis aeruginosa

11. Microcystis delicatissima

12. Merismopedia glauca

13. Merismopedia punctata

14. Oscillatoria sp.

15. Phormidium sp.

16. Spirulina $\mathrm{sp}$.

17. Synechococcus sp.

18. Synechocystis aquatilis

\section{Chlorophyta}

19. Actinastrum hantzschii

20. Asterococcus sp.

21. Closterium ehrenbergii

22. Coelastrum microporum

23. Cosmarium sp.

24. Crucigenia tetrapedia

25. Chlorella vulgaris

26. Dictyosphaerium pulchellum

27. Eudorina elegans

28. Micractinium pusillum

29. Monoraphidium minutum
30. Monoraphidium tortile

31. Oocystis sp.

32. Pediastrum simplex

33. Scenedesmus acuminatum

34. Schroederia setigera

35. Sphaerocystis schroeteri

36. Staurastrum sp.

Chrysophyta

37. Mallomonas sp.

Bacillariophyta

38. Aulacoseira granulata

39. Cyclotella meneghiniana

40. Denticula sp.

41. Gomphonema sp.

42. Navicula sp.

43. Nitzschia $\mathrm{sp}$.

44. Rhizosolenia sp.

45. Synedra sp.

Euglenophyta

46. Euglena sp.

47. Trachelomonas volvocina

\section{Cryptophyta}

48. Cryptomonas erosa

49. Chroomonas sp.

Pyrrophyta

50. Peridinium sp.

\section{Embalse La Mariposa}

En la Tabla 4 se presenta la lista de especies del fitoplancton presentes en el embalse La Mariposa durante el período de estudio. Se lograron identificar 50 especies. Las divisiones más diversas fueron las Chlorophyta (algas verdes) y las Cyanobacteria, cada una con 18 especies, seguidas por las Bacillariophyta con 8 especies. La especie dominante durante casi todo el período de estudio fue Cryptomonas erosa (Cryptophyta). Otras especies abundantes fueron Chroomonas sp. (Cryptophyta), Mallomonas sp. (Chrysophyta), Chlorella vulgaris y Schroederia setigera (Chlorophyta) y Merismopedia elegans
(Cyanobacteria). Aulacoseira granulata (Bacillariophyta) fue abundante durante los meses de septiembre y febrero.

La figura 3 presenta las variaciones de abundancia, biomasa y de producción primaria del fitoplancton durante el período de estudio.

La abundancia del fitoplancton, presentó el mismo patrón de variación que la biomasa, con picos de 35.5 x $10^{9}$ org. $/ \mathrm{m}^{2}$ y 34.8 x $10^{9}$ org. $/ \mathrm{m}^{2}$ en septiembre y febrero, respectivamente. E1 grupo dominante fue el de las Cryptophyta durante casi todo el período de estudio, con proporciones relativas que a veces superaron el $80 \%$. Las Chlorophyta dominaron en enero, durante la circulación completa de las aguas, y 

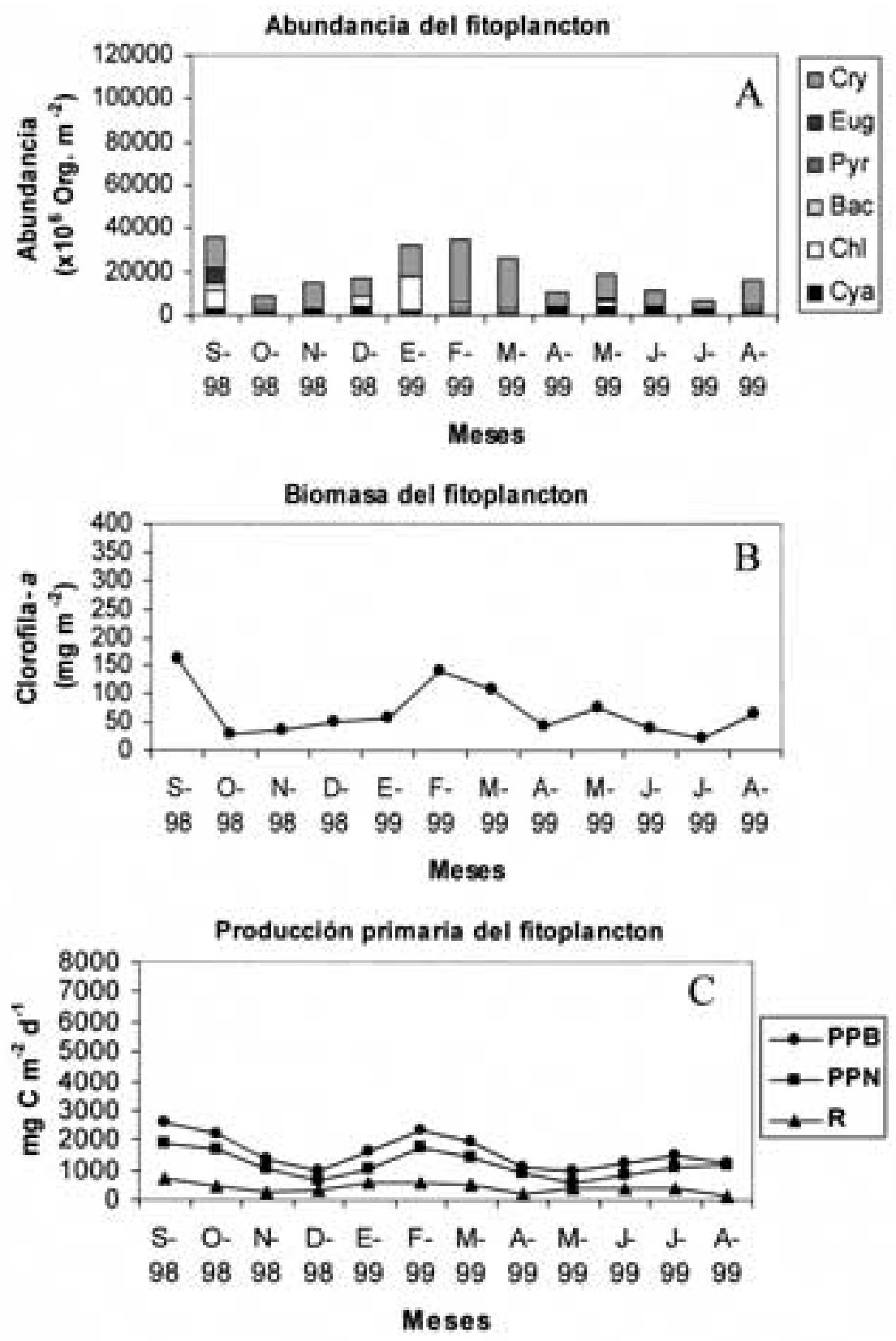

Figura 3. Fitoplancton del embalse La Mariposa. A. Abundancia, B. Biomasa, C. Producción primaria. Phytoplankton from La Mariposa reservoir. A. Abundance, B, Biomass, C. Primary production.

fue el grupo co-dominante durante la mayor parte del período de estudio. Las Cyanobacteria fue el siguiente grupo en lo que respecta a proporciones relativas, con una contribución de más del $30 \%$ del total durante el mes de julio, cuando se presentó el mínimo de abundancia $\left(6.2 \times 10^{9} \mathrm{org} . / \mathrm{m}^{2}\right)$. La contribución de los otros grupos del fitoplancton fue baja con respecto al total, a excepción de las Euglenophyta durante septiembre, con una contribución cercana al 
Tabla 5. Lista de especies del fitoplancton encontradas en el embalse Lagartijo. List of phytoplankton species colleted in Lagartijo reservoir.

\section{Cyanobacteria}

1. Anabaena aphanizomenoides

2. Aphanothece sp.

3. Cylindrospermopsis raciborskii

4. Chroococcus limneticus

5. Chroococcus minimus

6. Chroococcus pallidus

7. Dactylococcopsis acicularis

8. Gomphosphaeria sp.

9. Lyngbya limnetica

10. Microcystis holsatica

11. Oscillatoria annae

12. Spirulina laxissima

13. Synechococcus leopoliensis

14. Synechococcus linearis

15. Synechocystis aquatilis

\section{Chlorophyta}

16. Actinotaenium minutissimum

17. Botryococcus braunii

18. Closterium dianae

19. Coelastrum microporum

20. Coelastrum reticulatum

21. Crucigenia fenestra

22. Crucigenia quadrata

23. Crucigeniella rectangularis

24. Chlamydomonas sp.

25. Chlorella saccarophila

26. Chlorella vulgaris

27. Dictyosphaerium pulchellum

28. Elakatothrix gelatinosa

29. Eudorina sp.

30. Gyoerffyana humicola

31. Kirchneriella contorta

32. Monoraphidium minutum

33. Monoraphidium tortile

34. Nephrochlamys sp.

35. Nephrocytium aghardianum

36. Oocystis eremosphaeria

37. Oocystis lacustris
38. Oocystis parva

39. Phacotus sp.

40. Scenedesmus arcuata

41. Scenedesmus ecornis

42. Schroederia setigera

43. Sphaerocystis schroeteri

44. Spirotaenia minuta

45. Staurastrum tetracerum

46. Tetraedron incus

47. Tetraedron sp.

48. Tetrastrun triangulare

49. Volvox sp.

\section{Chrysophyta}

50. Mallomonas sp.

\section{Bacillariophyta}

51. Actinella sp.

52. Achnanthes sp.

53. Aulacoseira granulata

54. Cyclotella meneghiniana

55. Cymbella sp.

56. Denticula sp.

57. Gomphonema gracile

58. Navicula $\mathrm{sp.}$

59. Nitzschia sp.

60. Rhizosolenia sp.

61. Stephanodiscus hantzschii

62. Synedra ulna

Euglenophyta

63. Euglena sp.

64. Trachelomonas volvocina

\section{Cryptophyta}

65. Cryptomonas erosa

66. Chroomonas nordstedtii

\section{Pyrrophyta}

67. Peridinium sp.
$20 \%$ del total, y de las Bacillariophyta durante septiembre y febrero, meses en que su contribución fue cercana al $10 \%$.

El máximo valor de biomasa (como clorofilaa) fue de $161.77 \mathrm{mg} / \mathrm{m}^{2}$, y se registró durante el mes de septiembre de 1998; otro pico de magnitud similar se registró en febrero de 1999, después de la mezcla completa de las aguas del embalse (valor de $140.16 \mathrm{mg} / \mathrm{m}^{2}$ ). El valor promedio fue de $68.74 \mathrm{mg} / \mathrm{m}^{2}$ (media por unidad de volumen $=41.92 \mu \mathrm{g} / \mathrm{l})$. El patrón de la variación de la biomasa coincidió con los patrones de variación de la conductividad, nitrógeno total, fósforo total y los nitratos y ortofosfatos (Ortaz et al., 1999). El fitoplancton, por lo tanto, respondió directamente a la mayor disponibilidad de nutrientes en el agua, los cuales fueron resuspendidos durante la época de circulación de las aguas (enero a marzo de 1999) y cuando se bombeó agua desde otros embalses (septiembre de 1998). 
González \& Ortaz (1998), realizando experimentos de fertilización con N y $\mathrm{P}$ en microcosmos en este embalse, demostraron que el enriquecimiento con estos nutrientes, a pesar de las altas concentraciones presentes en las aguas naturales, condujeron a un aumento de la biomasa del fitoplancton dentro de los microcosmos. Esto indica que el fitoplancton puede seguir aumentando sus densidades si continúa el proceso de eutrofización del embalse, ya que la entrada de nutrientes al embalse continúa siendo elevada.

La PPB del fitoplancton, presentó la misma tendencia que la abundancia y la biomasa del fitoplancton, con picos de 2633.29 y $2366.01 \mathrm{mg} \mathrm{C} \mathrm{m}^{-2} \mathrm{~d}^{-1}$ durante los meses de septiembre y febrero, respectivamente. El primer pico pudo deberse a la entrada de nutrientes por escorrentía en plena estación de lluvias del año 1998, mientras que el pico de febrero pudo ser consecuencia de una mayor disponibilidad de nutrientes en la columna de agua como consecuencia de la circulación de las aguas. Un pico menor de producción primaria bruta $(\mathrm{PPB})$ de $1516.66 \mathrm{mg} \mathrm{C} \mathrm{m}^{-2} \mathrm{~d}^{-1}$ registrado en julio, pudo deberse al ligero aumento en la conductividad (aumento de la concentración de electrólitos) y al aumento en las concentraciones de nitratos, amonio y ortofosfatos (Ortaz et al., 1999). El menor valor de la PPB fue de $968.21 \mathrm{mg} \mathrm{C} \mathrm{m}^{-2} \mathrm{~d}^{-1}$, y se registró en mayo de 1999.

La PPB promedio fue de $1601.61 \mathrm{mg} \mathrm{C} \mathrm{m}^{-2} \mathrm{~d}^{-1}$, valor que puede considerarse alto, y la respiración representó el $26 \%$ de este valor.

\section{Embalse Lagartijo}

En la Tabla 5 se presenta la lista de especies del fitoplancton presentes en el embalse Lagartijo identificadas durante el período de estudio. Se lograron identificar 67 especies, siendo las más diversas las Chlorophyta (algas verdes) con 34 especies.

La figura 4 muestra las variaciones de abundancia, biomasa y de producción primaria del fitoplancton. La abundancia del fitoplancton también fue relativamente baja en este ecosis- tema, con valores entre $4.6 \times 10^{9}$ org. $/ \mathrm{m}^{2}$ (mayo) y $27.2 \times 10^{9} \mathrm{org} . / \mathrm{m}^{2}$ (diciembre). El pico de abundancia de diciembre se debió al notable aumento de densidad de la especie Sphaerocystis schroeteri (alga verde). Otros picos secundarios de abundancia se registraron en octubre y en julio, debido al desarrollo de las poblaciones de Gomphonema gracile (Bacillariophyta o diatomea) Lyngbya limnetica (Cyanobacteria) y Cryptomonas erosa (Cryptophyta), respectivamente.

Las algas verdes dominaron el fitoplancton durante casi todo el lapso de estudio, tal como se aprecia en la figura 4A. Las Chlorophyta llegaron a representar más del $80 \%$ del total del fitoplancton presente en diciembre, cuando se desarrolló la especie colonial Sphaerocystis schroeteri, tal como se explicó anteriormente. En octubre y noviembre, las Bacillariophyta dominaron ligeramente sobre las Chlorophyta, debido al desarrollo de las poblaciones de Gomphonema gracile. En febrero hubo una contribución importante de la diatomea Stephanodiscus hantzschii, que generó un ligero aumento en la proporción de las diatomeas a casi el $25 \%$ del total. Las Cyanobacteria contribuyeron con menos del $10 \%$ del total de septiembre a diciembre, con un ligero aumento en enero a más del $25 \%$ debido al desarrollo de las poblaciones de Synechococcus spp., para disminuir a menos del $10 \%$ en febrero nuevamente. A partir de marzo, la contribución de este grupo aumentó gradualmente, hasta contribuir con más del $80 \%$ del total del fitoplancton en junio, debido al incremento en las densidades de Lyngbya limnetica y Cylindrospermopsis raciborskii. En julio, Lyngbya limnetica fue la especie dominante del fitoplancton. Esta alta abundancia de las Cyanobacteria en el período de lluvias también fue registrado por Infante et al., (1992) y por González et al. (1997).

La mayor contribución de las Cryptophyta se registró en julio de 1999, con cerca de un $25 \%$ del total, cuando Cryptomonas erosa fue la especie co-dominante. Durante el resto del período, su contribución al fitoplancton del embalse Lagartijo fue baja, aunque en septiembre ésta 


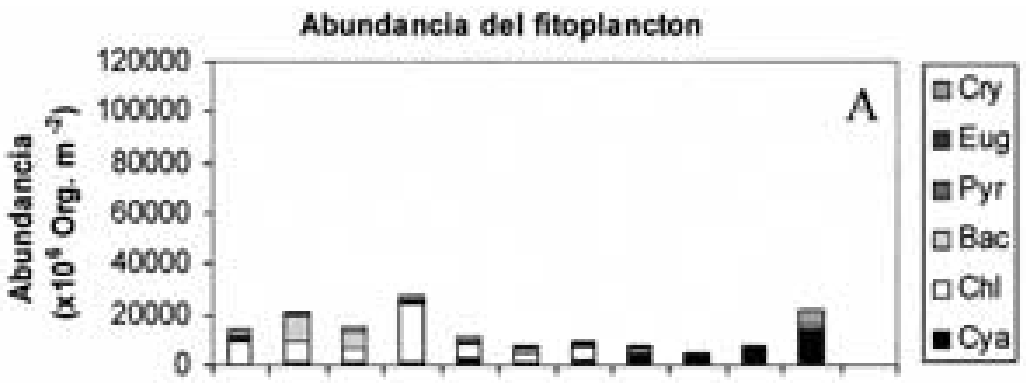

S. O. N. D. E. F. M. A. M. J. J. A.

$\begin{array}{llllllllllll}98 & 98 & 98 & 98 & 99 & 99 & 99 & 99 & 99 & 99 & 99 & 99\end{array}$

Meses
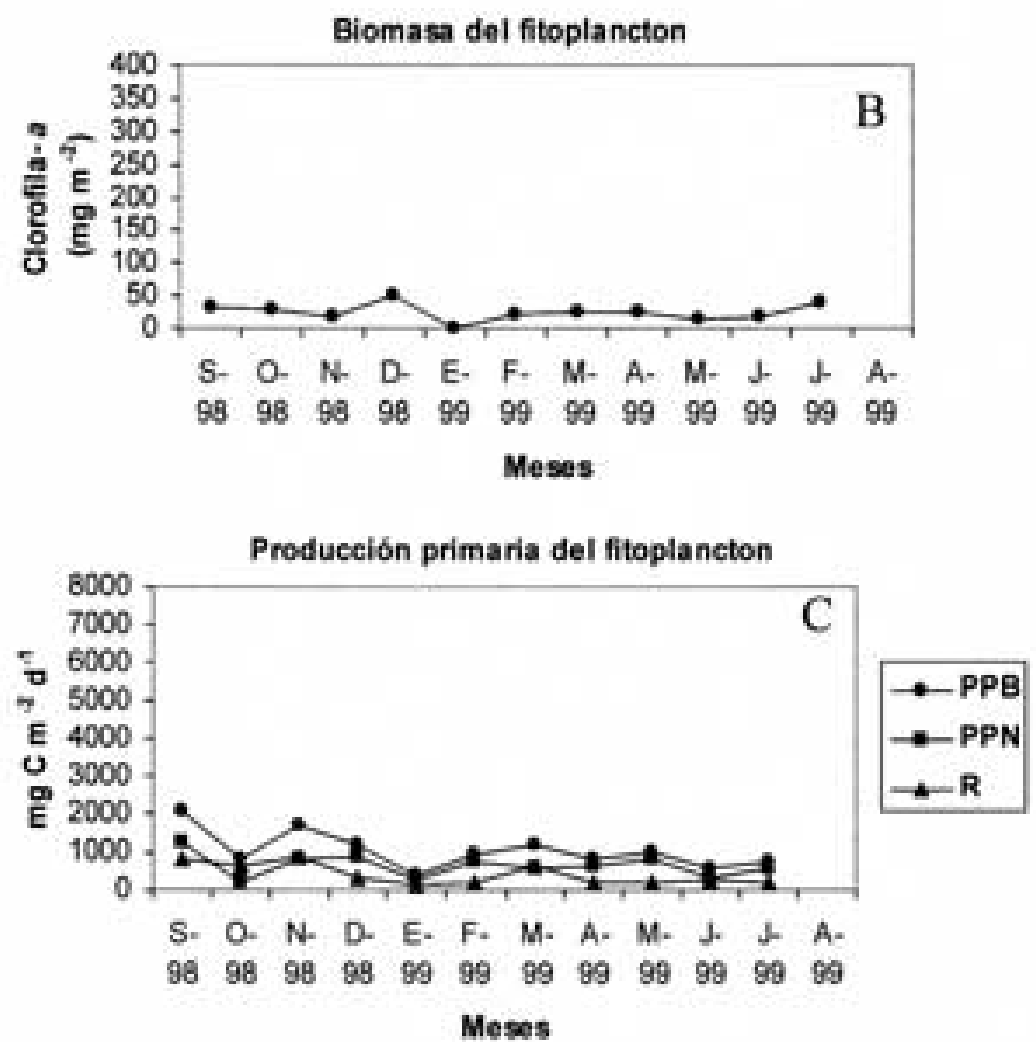

Figura 4. Fitoplancton del embalse Lagartijo. A. Abundancia, B. Biomasa, C. Producción primaria. Phytoplankton from Lagartijo reservoir. A. Abundance, B, Biomass, C. Primary production.

superó el $20 \%$. El resto de los grupos estuvo presente en muy bajas proporciones durante el lapso septiembre de 1998 - julio de 1999.

La biomasa, medida como concentración de clorofila- $a$, varió entre $0.01 \mathrm{mg} / \mathrm{m}^{2}$ en enero, y $50.01 \mathrm{mg} / \mathrm{m}^{2}$ en diciembre (Fig. 4B), con una media de $24.99 \mathrm{mg} / \mathrm{m}^{2}$. Estos valores se pueden considerar bajos, y se explican por las relativamente bajas concentraciones de nutrientes, especialmente de ortofosfatos (Ortaz et al., 1999). La concentración promedio de clorofila- $a$, en términos volumétricos, fue de $5.78 \mu \mathrm{g} / \mathrm{l}$. En líneas generales, la biomasa y la abundancia del fitoplancton presentaron tendencias similares. 
La producción primaria bruta (PPB) presentó grandes variaciones durante el período de estudio (Fig. 4C), con valores entre $376.05 \mathrm{mg} \mathrm{C} \mathrm{m}^{-2} \mathrm{~d}^{-1}$ en enero y $2087.80 \mathrm{mg} \mathrm{C} \mathrm{m}^{-2} \mathrm{~d}^{-1}$ en septiembre. Estos valores se pueden considerar de bajos a moderados. El menor valor de producción primaria coincidió con el menor valor de biomasa, cuando dominaron las especies de pequeño tamaño, como Cryptomonas erosa y Chlorella spp. (unicelulares) y Monoraphidium spp. (filamentosas). Las diatomeas presentaron bajas densidades durante este mes. El aumento de la PPB en julio coincidió con el incremento de la abundancia y de la biomasa durante este mes. En promedio, la PPB fue de $1031 \mathrm{mg} \mathrm{C} \mathrm{m}^{-2} \mathrm{~d}^{-1}$, y la respiración del fitoplancton representó el $38 \%$ de la PPB.

Debido a su condición oligotrófica, este embalse fue el que presentó los menores valores de abundancia, biomasa y producción primaria de los cinco embalses estudiados.

\section{Embalse La Pereza}

En la Tabla 6 se presenta la lista de las especies identificadas en el embalse La Pereza. Se lograron identificar 48 especies, siendo las más diversas las Chlorophyta, con 21 especies. Cryptomonas erosa (Cryptophyta) y las diatomeas Cyclotella meneghiniana, Aulacoseira granulata, Synedra sp. y Navicula sp. dominaron el fitoplancton durante casi todo el período de estudio. Las Cyanobacteria Synechococcus sp. y Synechocystis aquatilis, y el alga verde Chlorella vulgaris dominaron el fitoplancton durante el mes de junio.

La abundancia, biomasa y producción primaria del fitoplancton se presentan en la Fig. 5. Las

Tabla 6. Lista de las especies del fitoplancton encontradas en el embalse La Pereza. List of phytoplankton species colleted in La Pereza reservoir.

\section{Cyanobacteria}

1. Cylindrospermopsis raciborskii

2. Chroococcus sp.

3. Dactylococcopsis acicularis

4. Gomphosphaeria sp.

5. Lyngbya limnetica

6. Marssoniella sp.

7. Merismopedia sp.

8. Microcystis holsatica

9. Oscillatoria sp.

10. Phormidium sp.

11. Rhaphidiopsis sp.

12. Spirulina sp.

13. Synechococcus sp.

14. Synechocystis aquatilis

\section{Chlorophyta}

15. Actinastrum hantzschii

16. Asterococcus sp.

17. Closterium sp.

18. Coelastrum sp.

19. Cosmarium sp.

20. Chlamydomonas sp.

21. Chlorella vulgaris

22. Chodatella sp.

23. Crucigenia sp.

24. Dictyosphaerium sp.

25. Elakatohrix gelatinosa

26. Eudorina sp.

27. Monoraphidium sp.
28. Nephrocytium sp.

29. Oocystis sp.

30. Pandorina sp.

31. Scenedesmus ecornis

32. Schroederia setigera

33. Sphaerocystis schroeteri

34. Staurastrum sp.

35. Tetraedron $\mathrm{sp}$.

\section{Bacillariophyta}

36. Aulacoseira granulata

37. Cyclotella meneghiniana

38. Eunotia sp.

39. Gomphonema sp.

40. Navicula sp.

41. Nitzschia sp.

42. Stephanodiscus hantzschii

43. Synedra sp.

Euglenophyta

44. Euglena sp.

45. Trachelomonas sp.

Cryptophyta

46. Cryptomonas erosa

47. Chroomonas sp.

Pyrrophyta

48. Peridinium sp. 
Cryptophyta dominaron el fitoplancton en noviembre (aproximadamente $75 \%$ del total), debido seguramente a la alta cantidad de materia orgánica presente en las aguas (Fig. 5A). Su contribución al total del fitoplancton fue disminuyendo gradualmente hasta junio, cuando su proporción relativa fue de aproximadamente el 10 $\%$. De febrero a mayo, la proporción relativa de las Bacillariophyta (diatomeas) fue en aumento, hasta representar más del $50 \%$ del total del fitoplancton. La contribución de las Cyanobacteria fue menor al $10 \%$ de noviembre a abril, para aumentar gradualmente hasta más del $50 \%$ en junio. Las Chlorophyta, por otra parte, presentaron sus mayores proporciones relativas en junio y febrero, con porcentajes superiores al $20 \%$. Las Euglenophyta y las Pyrrophyta estuvieron presentes en muy bajas proporciones durante todo el período de estudio. Los valores mínimo y máximo fueron $2.8 \times 10^{9} \mathrm{org} . / \mathrm{m}^{2}$ en junio, y $102.9 \mathrm{x}$ $10^{9} \mathrm{org} . / \mathrm{m}^{2}$ en abril. Este último valor se puede considerar como muy alto.
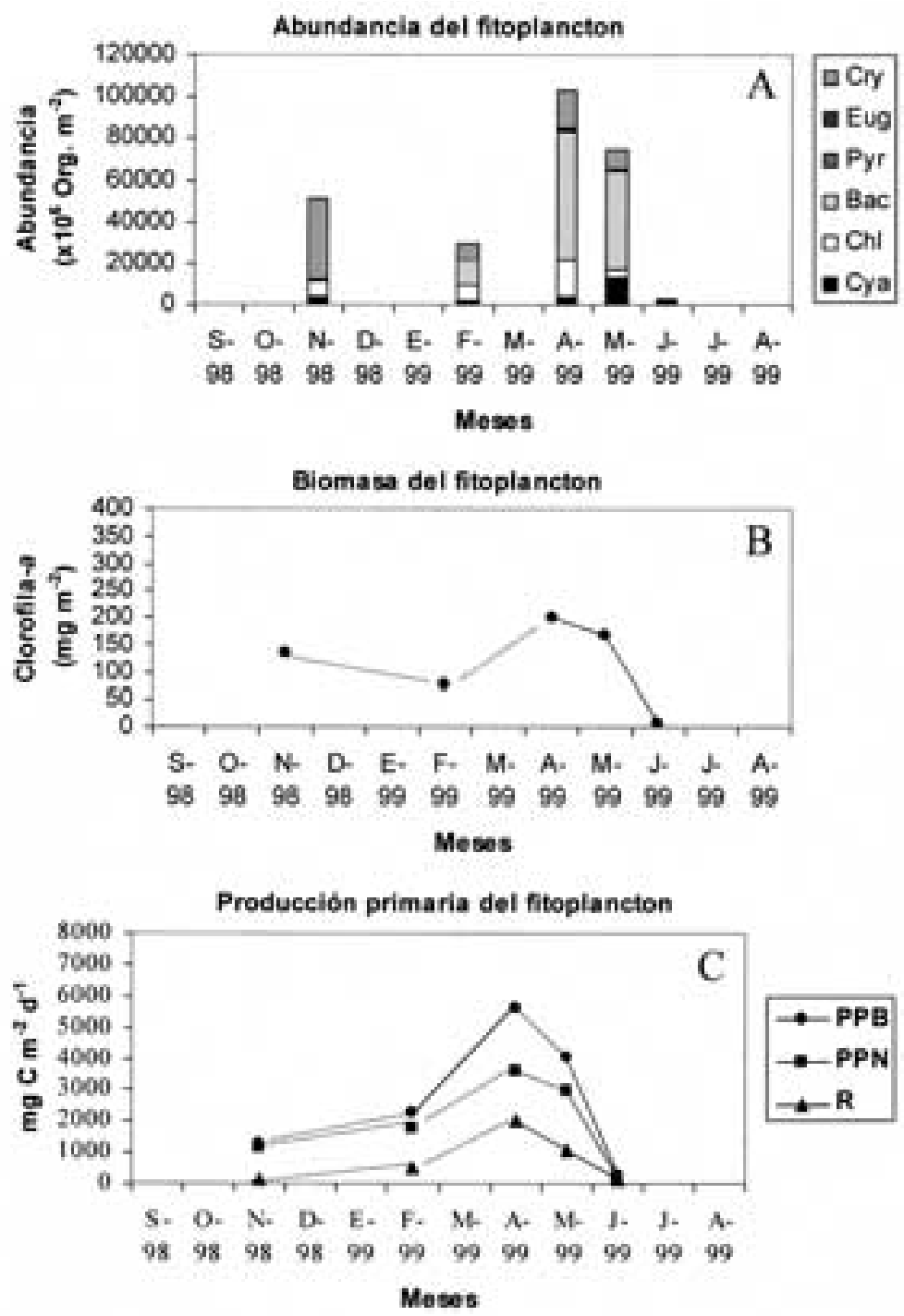

Figura 5. Fitoplancton del embalse La Pereza. A. Abundancia, B. Biomasa, C. Producción primaria. Phytoplankton from La Pereza reservoir. A. Abundance, B, Biomass, C. Primary production. 
Tabla 7. Lista de especies del fitoplancton encontradas en el embalse Quebrada Seca. List of phytoplankton species collected in Quebrada Seca reservoir.

\section{Cyanobacteria}

1. Anabaena sp.

2. Aphanocapsa sp.

3. Aphanothece sp.

4. Cylindrospermopsis raciborskii

5. Chroococcus sp.

6. Dactylococcopsis acicularis

7. Gomphosphaeria sp.

8. Lyngbya limnetica

9. Merismopedia elegans

10. Microcystis aeruginosa

11. Oscillatoria sp.

12. Rhaphidiopsis sp.

13. Spirulina sp.

14. Synechococcus sp.

15. Synechocystis aquatilis

\section{Chlorophyta}

16. Actinastrum hantzschii

17. Asterococcus sp.

18. Closterium sp.

19. Coelastrum sp.

20. Cosmarium sp.

21. Crucigenia sp.

22. Chlamydomonas sp.

23. Chlorella vulgaris

24. Dictyosphaerium pulchellum

25. Elakatothrix gelatinosa

26. Eudorina sp.

27. Monoraphidium sp.

28. Nephrocytium sp.
29. Oocystis sp.

30. Pandorina sp.

31. Phacotus sp.

32. Pediastrum sp.

33. Scenedesmus sp.

34. Schroederia setigera

35. Sphaerocystis sp.

36. Tetraedron sp.

\section{Chrysophyta}

37. Mallomonas sp.

\section{Bacillariophyta}

38. Aulacoseira granulata

39. Cyclotella sp.

40. Navicula $\mathrm{sp}$.

41. Nitzschia sp.

42. Rhizosolenia sp.

43. Synedra sp.

Euglenophyta

44. Euglena sp.

45. Trachelomonas sp.

\section{Cryptophyta}

46. Cryptomonas erosa

47. Chroomonas sp.

Pyrrophyta

48. Peridinium sp.
La biomasa, estimada como concentración de clorofila- $a$, varió entre $5.48 \mathrm{mg} / \mathrm{m}^{2}$ en junio, y $199.21 \mathrm{mg} / \mathrm{m}^{2}$ en abril (Fig. 5B), con una media de $117.10 \mathrm{mg} / \mathrm{m}^{2}$. En términos de unidades de volumen, el promedio fue de $44.37 \mu \mathrm{g} / 1$. Las condiciones de hipoxia en toda la columna de agua en junio, limitaron el crecimiento del fitoplancton, que presentó una notable disminución de su biomasa y abundancia de mayo a junio. El patrón de variación de la abundancia del fitoplancton coincidió con el de la variación de biomasa.

Los bajos valores de biomasa en junio se debieron a la dominancia de especies de pequeño tamaño, como Synechococcus sp., Synechocystis aquatilis y Chlorella vulgaris. El pico de biomasa en abril y los altos valores de mayo se debie- ron a una alta tasa de desarrollo de las diatomeas Cyclotella meneghiniana, Aulacoseira granulata, Synedra sp. y Navicula sp. y de la especie flagelada Cryptomonas erosa, como consecuencia de la alta disponibilidad de nutrientes en el cuerpo de agua. La alta abundancia de diatomeas le confirieron al agua un color pardo amarillento en estos meses. La alta abundancia del fitoplancton en los meses de abril y mayo, fueron responsables de los menores valores de transparencia del agua y de los mayores valores del coeficiente de atenuación de la luz registrados en las aguas del embalse (Ortaz et al., 1999).

La producción primaria bruta del fitoplancton siguió la misma tendencia de la abundancia y de la biomasa (Fig. 5C). El pico de producción se 
registró en abril, con un valor de $5618.67 \mathrm{mg} \mathrm{C}$ $\mathrm{m}^{-2} \mathrm{~d}^{-1}$, valor comparable a uno de los registrados en uno de los ecosistemas más productivos y eutrofizados del país, como lo es el Lago de Valencia (Infante, 1997). Esta alta PPB fue la responsable de la sobresaturación de oxígeno registrada durante el mes de abril (Ortaz et al.,1999). En mayo también se registró un alto valor de PPB, equivalente a $4055.85 \mathrm{mg} \mathrm{C} \mathrm{m}^{-2} \mathrm{~d}^{-1}$, responsable de la sobresaturación de oxígeno superficial en este mes. En cambio, durante junio, debido a la limitación causada por los bajos valores de oxígeno disuelto en el agua, la producción disminuyó a $264.49 \mathrm{mg} \mathrm{C} \mathrm{m}^{-2} \mathrm{~d}^{-1}$. La PPB promedio fue de $2690.68 \mathrm{mg} \mathrm{C} \mathrm{m}^{-2} \mathrm{~d}^{-1}$, mientras que la respiración promedio fue de $753.94 \mathrm{mg} \mathrm{C} \mathrm{m}^{-2}$ $\mathrm{d}^{-1}$, lo cual representó el $29 \%$ de la PPB.

\section{Embalse Quebrada Seca}

La Tabla 7 presenta la lista de especies del fitoplancton encontradas en el período de estudio. En total, se encontraron 48 especies, siendo las Chlorophyta las más diversas con 21 especies. La Cyanobacteria Cylindrospermopsis raciborskii dominó durante casi todo el período de estudio.

La figura 6A muestra que las Cyanobacteria dominaron el fitoplancton de octubre a marzo, con proporciones superiores al $60 \%$ del total. Cylindrospermopsis raciborskii, Oscillatoria sp., y Anabaena sp. estuvieron presentes en altas densidades en este período. Las Cyanobacteria codominaron con las algas verdes en junio, con una proporción de $50 \%$; las Cyanobacteria Dactylococcopsis acicularis y Synechocystis aquatilis, y las Chlorophyta Chlorella vulgaris y Schroederia setigera fueron las especies predominantes en este mes. En mayo dominaron las Bacillariophyta, debido al desarrollo de las poblaciones de Aulacoseira granulata. Las Chlorophyta co-dominaron también en este mes, debido a las altas abundancias de Phacotus sp. y Nephrocytium sp. Las Cryptophyta presentaron sus mayores proporciones relativas en octubre, superando el $10 \%$ del total. En el resto del período de estudio, este grupo presentó bajas contribuciones relativas al total del fitoplancton presente, al igual que los demás grupos de esta comunidad.

La abundancia del fitoplancton varió entre $26.9 \times 10^{9} \mathrm{org} . / \mathrm{m}^{2}$ y $69.3 \times 10^{9} \mathrm{org} . / \mathrm{m}^{2}$ en octubre y diciembre, respectivamente, con un promedio de $42.5 \times 10^{9} \mathrm{org} . / \mathrm{m}^{2}$.

La biomasa del fitoplancton presentó su máximo valor durante marzo, con una concentración de clorofila- $a$ de $355.35 \mathrm{mg} / \mathrm{m}^{2}$ (Fig. 6B). La mayor disponibilidad de ortofosfatos en la zona eufótica hizo posible este valor extremo (Ortaz et al., 1999). Los menores valores se registraron en mayo $\left(53.73 \mathrm{mg} / \mathrm{m}^{2}\right)$ y diciembre $\left(59.20 \mathrm{mg} / \mathrm{m}^{2}\right)$, con un promedio de 134.74 $\mathrm{mg} / \mathrm{m}^{2}$ (en términos volumétricos, el promedio fue de $62.71 \mu \mathrm{g} / 1)$.

La abundancia del fitoplancton presentó una tendencia inversa a la de la biomasa del fitoplancton. El pico de abundancia de diciembre se debió a las altas densidades de Cylindrospermopsis raciborskii y gran abundancia de especies de pequeño tamaño (Cryptomonas erosa, Chlorella vulgaris) o de filamentos delgados (Oscillatoria sp., Rhaphidiopsis sp.), las cuales poseen menor contenido de pigmentos fotosintéticos que las que predominaron en marzo, como lo fueron los grandes filamentos de Anabaena sp. Otro pico de abundancia se presentó en mayo, cuando la diatomea Aulacoseira granulata fue dominante. Esta diatomea tiene en el citoplasma vacuolas de gran tamaño, por lo que el contenido de clorofila- $a$ es limitado, lo cual explica los mínimos valores de biomasa encontrados.

La producción primaria bruta mostró la misma tendencia que la biomasa del fitoplancton, con valores entre 1762.50 y $3493.99 \mathrm{mg} \mathrm{C} \mathrm{m}^{-2} \mathrm{~d}^{-1}$ en mayo y marzo, respectivamente (Fig. 6C), con una media de $2466.92 \mathrm{mg} \mathrm{C} \mathrm{m}^{-2} \mathrm{~d}^{-1}$. Estos valores se pueden considerar altos. La respiración representó en promedio el $21 \%$ de la PPB.

En la figura 7 se presentan, a modo de resumen, las proporciones promedios de los diferentes grupos del fitoplancton en cada uno de los embalses estudiados. Se puede notar que las Cyanobacteria dominaron en aquellos embalses con alto grado de eutrofización, en los que la turbiedad se debió en primer término a la materia orgánica (fitoplancton), como lo fueron Pao- 


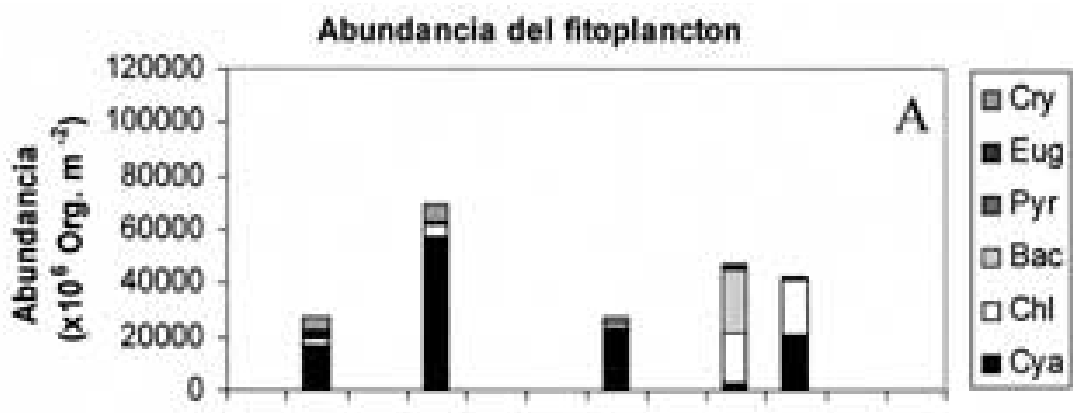

S. O. N. D. E. F. M. A. M- \& \&. A-

$\begin{array}{llllllllllll}98 & 98 & 98 & 98 & 99 & 99 & 99 & 99 & 99 & 99 & 99 & 99\end{array}$

Meses
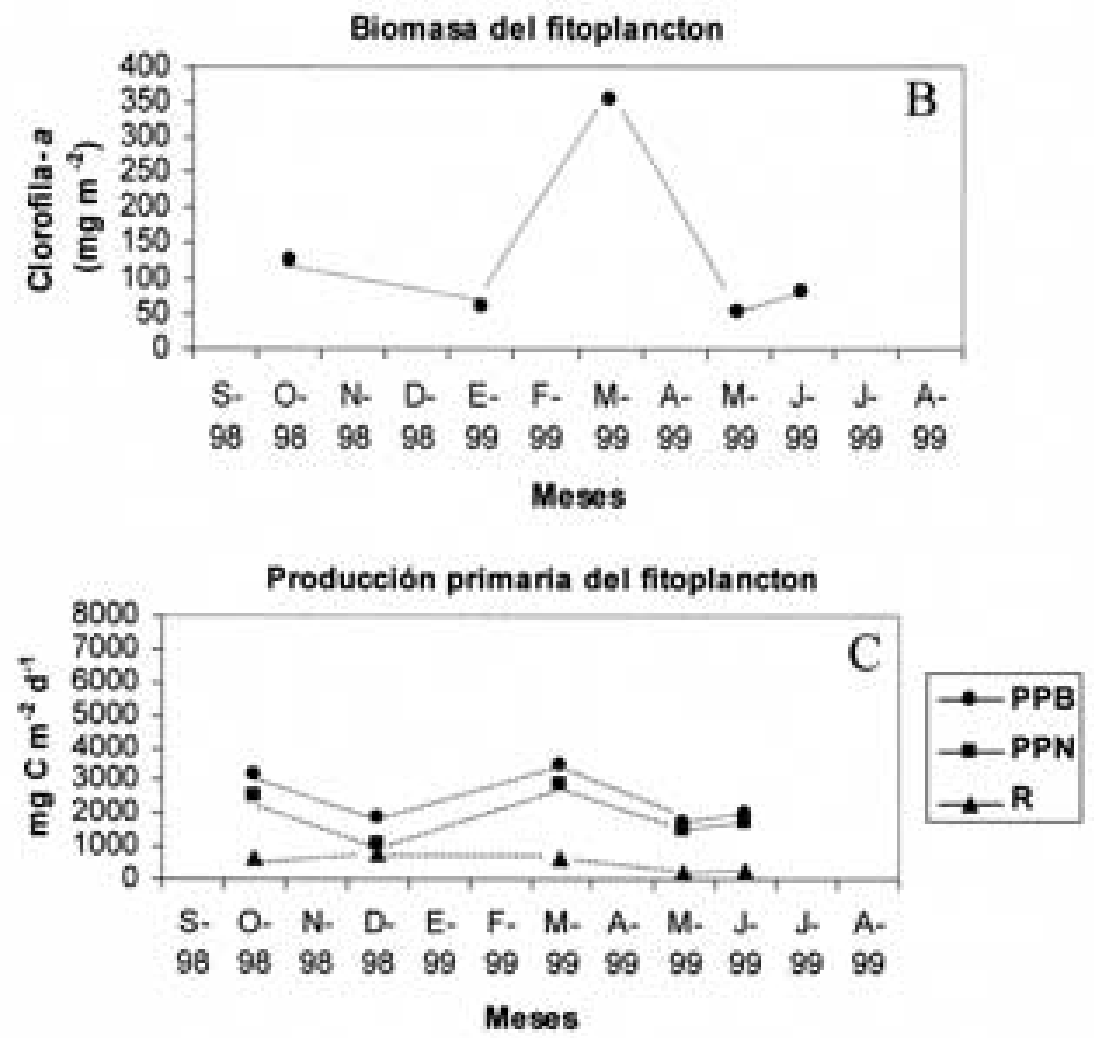

Figura 6. Fitoplancton del embalse Quebrada Seca. A. Abundancia, B. Biomasa, C. Producción primaria. Phytoplankton from Quebrada Seca reservoir. A. Abundance, B, Biomass, C. Primary production.

Cachinche y Quebrada Seca. En La Mariposa, las Cryptophyta fueron las predominantes y, a pesar de su condición hipereutrófica, las Cyanobacteria no fueron las predominantes. La Pereza presentó dominancia de las Bacillariophyta, seguida de las
Cryptophyta. En el único embalse oligotrófico de este estudio, Lagartijo, las Chlorophyta fueron las dominantes.

Una prueba de correlación no paramétrica de Spearman mostró que no hubo diferencias signi- 
ficativas $(\mathrm{p}<0.05)$ entre el orden jerárquico de los grupos del fitoplancton de E1 y E2 del embalse Pao-Cachinche $\left(r_{s}=0.9429\right)$, ya que pertenecen a un mismo embalse y con una condición hipereutrófica similar, y entre los embalses Lagartijo y Quebrada Seca $\left(r_{s}=0.9429\right)$, los cuales sólo difieren en el orden jerárquico de dos grupos: Cyanobacteria dominó en Quebrada Seca, seguida de Chlorophyta, mientras que en Lagartijo dominó Chlorophyta, seguida de Cyanobacteria.

\section{CONSIDERACIONES FINALES}

Además de las funciones de fuerza naturales (viento, temperatura y precipitación), el manejo de los cuerpos de agua estudiados afecta notablemente la dinámica de todos los parámetros determinados en todos los embalses evaluados, lo que lo convierte en una función de fuerza básica también (Tundisi \& Matsumura-Tundisi, 1990). Las variaciones de volumen de los embalses, especialmente en La Pereza, Quebrada Seca y La Mariposa, pudo contribuir enormemente con la resuspensión de los elementos nutritivos desde el fondo de la columna de agua, así como también a su reposición en la zona eufótica donde pudieron ser asimilados por el fitoplancton. Adicionalmente, las grandes fluctuaciones en el nivel de agua aumentan las posibilidades de erosión de la línea de costa de los embalses,

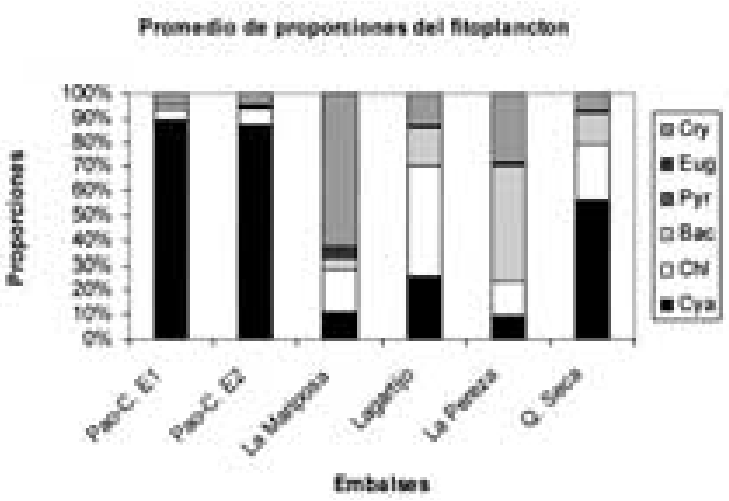

Figura 7. Proporciones promedios de los grupos del fitoplancton en los cinco embalses estudiados. Mean proportions of the phytoplankton groups in the five studied reservoirs. lo cual contribuiría a aumentar la carga de sedimentos inorgánicos y al pobre desarrollo de comunidades litorales.

En el caso del embalse Pao-Cachinche, las fluctuaciones en la abundancia, biomasa y producción primaria del fitoplancton se debieron a la entrada de nutrientes, al autosombreo de las algas y al tratamiento con los químicos $\mathrm{CuSO}_{4} \mathrm{y} \mathrm{AlSO}_{4}$.

La mayoría de los embalses evaluados en este estudio, y que son empleados para el suministro de agua potable, se encuentran eutrofizados, y en ellos predominan las Cyanobacteria y las Cryptophyta, con elevados valores de abundancia, biomasa y producción primaria, como consecuencia de la entrada excesiva de nutrientes desde sus cuencas de drenaje altamente erosionadas e intervenidas y a través de las aguas servidas sin tratamiento previo. Aún en el embalse oligotrófico, durante el inicio de la temporada de lluvias, las Cyanobacteria aumentaron sus proporciones relativas, lo cual puede ser un problema al momento de la utilización de las aguas, ya que todos estos son embalses que se emplean para el suministro de agua potable.

Los embalses La Mariposa, La Pereza y Quebrada Seca pudieran presentar mayores grados de eutrofización, de no ser por el bajo tiempo de residencia de sus aguas (Straskraba, 1999).

De los cuatro embalses eutrofizados, sólo en el embalse Pao-Cachinche se tiene previsto un plan para su mitigación (desestratificación), a ser aplicado próximamente. En todos los casos, el control de la entrada de nutrientes (especialmente fósforo) a los embalses, parece ser la vía para mitigar la eutrofización y controlar efectivamente el crecimiento de las algas indeseables (colonias y filamentos de Cyanobacteria, especialmente), de acuerdo a los sugerido por González \& Ortaz (1998), Ortaz et al. (1999) y González et al. (2000).

\section{AGRADECIMIENTOS}

A las empresas hidrológicas Hidroven, Hidrocentro e Hidrocapital, y a la empresa Hidroimpacto, por financiar los proyectos de investiga- 
ción. A Pasquale Molinaro, Pablo Borjas, Aldo Cróquer, Sandra Cano y Sandra Keri, por su colaboración en la ejecución del proyecto. Al personal de vigilancia y de operaciones de Hidrocapital y de Hidrocentro en los embalses La Mariposa, La Pereza y Pao-Cachinche, por su apoyo en los trabajos de campo.

\section{BIBLIOGRAFÍA}

CASTILlO, C., J. GÓMEZ \& C. MONTES. 1973. Embalses de Venezuela. Serie El Agua $\mathrm{N}^{\circ} 1$. Caracas.

EDMONDSON, W. T. 1969. Eutrophication in North America. Nat. Acad. Sci.: 124-149.

GINEZ, A. \& M. L. OLIVO. 1984. Inventario de los embalses con información básica para la actividad piscícola. I. Sinopsis de los embalses administrados por el MARNR. Ministerio del Ambiente $y$ de los Recursos Naturales Renovables. Serie Informes Técnicos DGSPOA/IT/183. Caracas, $142 \mathrm{pp}$.

GONZÁlEZ, E. J., M. ORTAZ, C. PEÑAHERRERA \& E. MONTES. 1997. Estudio control de algas en los embalses La Pereza, Quebrada Seca, La Mariposa, Lagartijo y Camatagua mediante técnicas de biomanipulación. Informe técnico presentado a las compañías Hidroimpacto C.A. e Hidrocapital.

GONZÁLEZ, E. J. \& M. ORTAZ. 1998. Efectos del enriquecimiento con N y P sobre la comunidad del fitoplancton en microcosmos de un embalse tropical (La Mariposa, Venezuela). Rev. Biol. Trop., 46: 27-34.

GONZÁlEZ, E. J., M. ORTAZ \& C. PEÑAHERRERA. 2000. Caracterización limnológica del embalse Pao-Cachinche (Estados Carabobo y Cojedes). Informe técnico presentado a las compañías Hidroven e Hidrocentro.

GONZÁLEZ, E. J. 2000. Caracterización limnológica del embalse El Pueblito (Estado Guárico, Venezuela). Trabajo de ascenso a la categoría de Profesor Agregado. Universidad Central de Venezuela. Caracas, 40 pp.

HARPER, D. 1992. Eutrophication of freshwaters. Principles, problems and restoration. Chapman \& Hall. London, 327 pp.
INFANTE, A. 1997. Primary production of phytoplankton in lake Valencia (Venezuela). Int. Revue ges. Hydrobiol., 82: 469-477.

INFANTE, A., O. INFANTE \& T. VEGAS. 1992. Caracterización limnológica de los embalses Camatagua, Guanapito y Lagartijo, Venezuela. Proyecto Multinacional de Medio Ambiente y Recursos Naturales. Organización de los Estados Americanos y Universidad Central de Venezuela, Caracas.

INFANTE, A., O. INFANTE. \& E. GONZÁLEZ. 1995. Caracterización limnológica de los embalses El Cuji y El Andino, Venezuela. Proyecto Multinacional de Medio Ambiente y Recursos Naturales. Organización de los Estados Americanos y Universidad Central de Venezuela, Caracas.

NUSCH, E. A. \& G. PALME. 1975. Biologische Methoden für der Praxis der Gewässeruntersuchung, Bestimmung des Chlorophyll-a und Phaeopigment-gehaltes in Oberflachenwässer. GWF-Wässer/Abwässer, 116: 562-565.

ORTAZ, M., E. J. GONZÁLEZ, J. MANDUCA, C. PEÑAHERRERA \& E. MONTES. 1999. Características limnológicas de los embalses La Pereza, Lagartijo, La Mariposa y Quebrada Seca y preservación del zooplancton como controlador de microalgas, mediante técnicas de biomanipulación. Informe técnico presentado a las compañías Hidroimpacto C.A. e Hidrocapital.

RYDING, S. O. \& W. RAST. 1992. El control de la eutroficación en lagos y pantanos. Ediciones Pirámide S.A. Unesco. Madrid, 385 pp.

SALAS, H. \& P. MARTINÓ. 1991. A simplified phosphorus trophic model state for warm-water tropical lakes. Wat. Res., 25: 341-350.

STRASKRABA, M. 1999. Retention time as a key variable of reservoir limnology. En: Theoretical reservoir ecology and its applications. J. G. Tundisi \& M. Straskraba (eds.): 385-410. International Institute of Ecology, Brazilian Academy of Sciences \& Blackhuys Publishers. São Carlos, Rio de Janeiro \& Leiden.

TUNDISI, J. G. \& T. MATSUMURA-TUNDISI. 1990. Limnology and eutrophication of Barra Bonita reservoir, S. Paulo State, Southern Brazil. Arch. Hydrobiol. Beih. Ergebn. Limnol., 33: 661-676.

WETZEL, R. G. \& G. E. LIKENS. 1991. Limnological analyses. $2^{\text {nd }}$ edition. Springer-Verlag, New York, $391 \mathrm{p}$. 